\title{
Pollution Assessment of Trace Elements in the Soil Planting Chinese Herbaceous Peony in Suzhou, China
}

\author{
L.H. Sun*† and S.B. Feng** \\ *School of Resources and Civil Engineering, Suzhou University, Anhui 234000, China \\ **Key Laboratory of Mine Water Resource Utilization of Anhui Higher Education Institute, Suzhou University, Anhui \\ 234000, China \\ †Corresponding author: L.H. Sun; sunlinh@126.com
}

Nat. Env. \& Poll. Tech. Website: www.neptjournal.com

Received: 02-02-2020

Revised: 22-02-2020

Accepted: 02-05-2020

Key Words:

Pollution assessment

Trace elements

Farmland soil

Chinese herbaceous peony

\begin{abstract}
Planting of the industrial crop is important for the rural revitalization in current China and the geological environment of soil is important for the development of the planting. In this study, twenty-eight surface soil samples in the farmland planting Chinese herbaceous peony in Suzhou have been collected and analysed for the concentrations of trace elements ( $\mathrm{As}, \mathrm{Co}, \mathrm{Cr}, \mathrm{Cu}, \mathrm{Ni}, \mathrm{Pb}$ and $\mathrm{Zn}$ along with $\mathrm{Fe}$ and $\mathrm{Mn}$ ). The results indicate that iron is the most abundant element, followed by manganese, zinc, chromium, lead, nickel, copper, arsenic and cobalt. They have coefficients of variation ranged between 0.058 and 0.561 , indicating that some of them might have multi-sources. The pollution indexes (including single pollution, geo-accumulation and the Nemerow composite indexes) indicate that the soil samples are no to slightly polluted. Multivariate statistical analyses (including correlation, cluster and factor analyses) have identified two sources (geogenic and agricultural related) responsible for the elemental concentrations in the soils.
\end{abstract}

\section{INTRODUCTION}

Rural revitalization strategy is one of the most important strategies in China (Lin 2020). It is an upgraded version of the new rural construction to avoid the decline of rural areas and agriculture in the process of urbanization (Ning 2019). Under this situation, the development of agriculture is becoming more and more important, because agriculture is not only the basic industry of China's national economy but also the cornerstone of the development of other industries.

As the most important aspect of agriculture, planting industry plays a decisive role in the development of modern agriculture, especially the characteristic planting industry, which refers to the special agricultural type with the characteristics of green and pollution-free, which makes full use of the unique advantageous agricultural resources in a certain region to develop and produce the planting products and processed products with high quality, high value and strong market competitiveness. And therefore, a large number of studies related to the spatial distribution, planting structure and market strategy et al. have been carried out (Liu \& Gu 2011, Qiao \& Wang 2012, Duan 2017).

Two factors are essential for the development of the characteristic planting industry, the product and the market. As to the product, the geological condition (including environment) is the most critical factor to determine whether the characteristic crops can be planted. For example, the famous Chinese tea "Mount Huangshan Mao Feng" and famous pear "Dangshan pear" can only be produced in the city of Huangshan and Dangshan in the south and north Anhui province, China, respectively, that's because of the special geological environment (Fu et al. 2009, Wu et al. 2010). To be one of the most important aspects of the geological environment, the soil is the foundation of planting industry. It does not only determine what crops are suitable for planting, but also determine the quality of crops.

Suzhou is an important agriculture base located in the north Anhui province, China, and therefore, the soil environment is important for the development of agriculture in the area, and a large number of studies have been carried out, including the pollution assessment, source approximation and remediation et al. (Sun \& Feng 2019, Sun 2020). In this study, a total of twenty-eight surface soil samples in the Chinese herbaceous peony plantation in Suzhou have been collected and the concentrations of nine kinds of elements have been measured, the goals of the study include: (1) getting the information about the pollution status and (2) identifying their sources. The study can provide scientific information for the planting of Chinese herbaceous peony because the root is the most important part to be used as a medicine, which is determined mostly by the quality of the soil. 


\section{MATERIALS AND METHODS}

\section{Study Area}

Suzhou is the north gate of the Anhui province, China. It is located at the south of the Huang-Huai plain, with adjacent to Xuzhou of Jiangsu and Heze of Shandong in the north, Yongcheng of Henan in the west, Suqian of Jiangsu in the east (Fig. 1). The annual precipitation is $857 \mathrm{~mm}$, with an average temperature of $14.4^{\circ} \mathrm{C}$. Agriculture is the main industry of the area. Wheat, cotton, vegetable production and pig, cattle, sheep and fish farming are leading agricultural industries.

However, with the acceleration of agricultural and industrial modernization, the situation of agricultural environmental pollution in Suzhou is becoming more and more severe, especially the pollution of pesticides and fertilizers, manure of livestock and poultry, agricultural film and agricultural waste (Zhao 2013). Simultaneously, with the development of regional economy, some other kinds of pollutions have also influenced the geological environment, including the soil, water and air (Sun \& Gui 2014, Sun \& Feng 2019, Sun 2020).

\section{Sampling and Analysis}

Peony, one of the ten famous flowers of China, is also known as the "Prime Minister of flowers" and the Mayflower God. It not only has a beautiful appearance but also has an extremely high edible and the medicinal value. Peony is the representative of modern characteristic planting industry in the area, which is mainly planted in the Haogou township in the northeast of Suzhou, which is $18 \mathrm{~km}$ to the urban area of Suzhou and $4 \mathrm{~km}$ to the East Railway Station of Suzhou, which is the main reason for its development of characteristic planting industry.

A total of twenty-eight surface soil samples in the farmland ( $<10 \mathrm{~cm}$ depth) planting Chinese herbaceous peony have been collected in June 2019, and the detailed sample distributions are shown in Fig. 1. All of the soil samples have been first air-dried in room temperature, and then the debris (animals and plants) have been manually removed. After these procedures, all the samples were parched for $24 \mathrm{~h}$ with $80^{\circ} \mathrm{C}$ in the dryer and then powdered to be smaller than 200 meshes $(<0.075 \mathrm{~mm})$. Finally, all the samples (powder) were compressed to be tablets under the pressure of $30 \mathrm{t}$.

The concentrations of nine elements (As, $\mathrm{Co}, \mathrm{Cr}, \mathrm{Cu}$, $\mathrm{Fe}, \mathrm{Mn}, \mathrm{Ni}, \mathrm{Pb}$ and $\mathrm{Zn}$ ) were analysed by the $\mathrm{X}$-ray fluorescence spectrometer (Innov-X Explorer 9000 SDD, USA) along with the National standard sediment sample of China

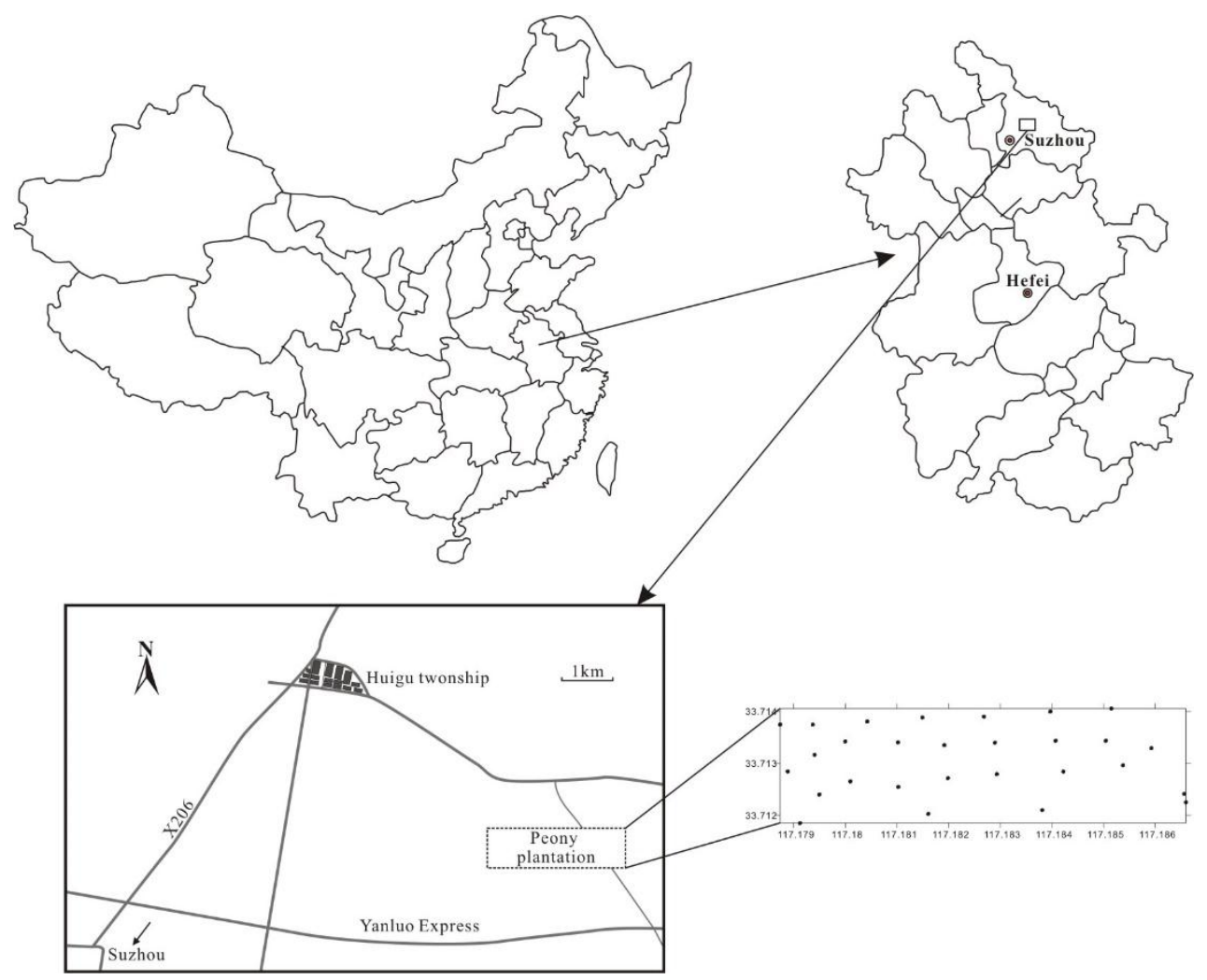

Fig. 1: Study area and sample locations. 
(GSS-16) for calibration in the Key Laboratory of Mine Water Resource Utilization of Anhui Higher Education Institute, Suzhou University. Previous studies indicated that the portable XRF instrument gave excellent correlation with the laboratory-based reference AAS method (Radu and Diamond 2009). After the analyses, the concentrations of elements have been recalculated by $\mathrm{C}_{\mathrm{m}}=\mathrm{C}_{\mathrm{t}} \times\left(\mathrm{S}_{\mathrm{s}} / \mathrm{S}_{\mathrm{m}}\right)$. Where, $\mathrm{C}_{\mathrm{m}}$ is the concentration of samples, $\mathrm{C}_{t}$ is the concentration of samples reported by the instrument, $\mathrm{S}_{\mathrm{s}}$ and $\mathrm{S}_{\mathrm{m}}$ are the standard and mean measured concentrations of the standard samples (GSS-16), respectively.

\section{Data Treatment}

All of the data were firstly processed for basic statistical analysis by the Mystat 12 software, and the minimum, maximum, mean, coefficient of variation and the p-value of the normal distribution test were obtained.

Then, a series of methods, including the single pollution index $\left(\mathrm{P}_{\mathrm{i}}\right)$ (Liang et al. 2011), the geo-accumulation index $\left(\mathrm{I}_{\text {geo }}\right)$ (Praveena et al. 2008) and the Nemerow composite index $\left(P_{n}\right)$ (Dai et al. 2008) were chosen for the quality evaluation of the samples.

Finally, some of the popularly used multivariate statistical methods in the environmental studies, including the correlation, cluster and factor analyses were applied in this study (through Mystat 12 software) for getting the qualitative information about the sources of elements.

\section{RESULTS AND DISCUSSION}

\section{Elemental Concentrations}

The analytical results of elemental concentrations are given in Table 1. It can be seen from the table that the elements in this study have the following decreasing order: $\mathrm{Fe}>\mathrm{Mn}>\mathrm{Zn}>$
$\mathrm{Cr}>\mathrm{Pb}>\mathrm{Ni}>\mathrm{Cu}>\mathrm{As}>\mathrm{Co}$, and their mean concentrations are 36182, 707, 74.2, 67.3, 39.2, 33.5, 19.9, 12.9 and 12.7 $\mathrm{mg} / \mathrm{kg}$, respectively.

Previous studies revealed that the coefficient of variation ( $\mathrm{CV}=$ standard deviation/mean) can be used for identifying the types of pollution distribution, high $\mathrm{CV}(>0.90)$ and low CV $(<0.10)$ mean high and low extents of spatial variations, respectively, which indirectly suggest the high and low degrees of anthropogenic contributions, respectively (Sarkar 2011). In this study, the $\mathrm{Co}, \mathrm{Fe}, \mathrm{Mn}, \mathrm{Pb}$ and $\mathrm{Zn}$ have low CVs $(<0.10)$, which means that the concentrations of these elements vary slightly from area to area indicating that they have relatively simple and homogeneous sources. Other elements have medium CVs (0.123-0.526), which indicate that they have moderate degrees of spatial variability indirectly suggesting the multi-source of them.

Moreover, the test of the normal distribution can also give information about the distribution of the elemental concentrations, because a normal distribution of the elemental concentration is always considered to represent a single source. In this study, most of the elements except for $\mathrm{Mn}$ and $\mathrm{Ni}$ have $\mathrm{p}$-values $>0.05$, indicating that they can pass the normal distribution test ( $\mathrm{p}$-value $>0.05$ ), and suggesting that the elements except for $\mathrm{Mn}$ and $\mathrm{Ni}$ might have a single source.

\section{Pollution Assessment}

Single pollution index $\left(\mathrm{P}_{\mathrm{i}}\right)$ has long been used for pollution assessment, which was defined by $\mathrm{P}_{\mathrm{i}}=\mathrm{C}_{\mathrm{m}} / \mathrm{C}_{\mathrm{s}}$. Where $\mathrm{C}_{\mathrm{m}}$ and $\mathrm{C}_{\mathrm{s}}$ are the concentration of sample and background, respectively. Previous studies revealed the pollution degrees can be classified to be three according to the threshold values of $\mathrm{P}_{\mathrm{i}}$ : no pollution $(<1)$, light pollution $(1-2)$, moderate pollution (2-3) and significant ( >3) (Liang et al. 2011).

Table 1: Descriptive statistics of elemental concentrations $(\mathrm{mg} / \mathrm{kg})$ in the soil samples.

\begin{tabular}{|c|c|c|c|c|c|c|c|c|c|}
\hline Species & As & $\mathrm{Co}$ & $\mathrm{Cr}$ & $\mathrm{Cu}$ & $\mathrm{Fe}$ & $\mathrm{Mn}$ & $\mathrm{Ni}$ & $\mathrm{Pb}$ & $\mathrm{Zn}$ \\
\hline $\mathrm{N}$ & 28 & 28 & 28 & 28 & 28 & 28 & 28 & 28 & 28 \\
\hline Min & 9.90 & 11.7 & 52.3 & 14.1 & 30888 & 587 & 7.40 & 33.9 & 62.4 \\
\hline Max & 17.2 & 13.6 & 84.0 & 32.0 & 39278 & 815 & 79.1 & 43.6 & 88.1 \\
\hline Mean & 12.9 & 12.7 & 67.3 & 19.9 & 36182 & 707 & 33.5 & 39.2 & 74.2 \\
\hline $\mathrm{CV}$ & 0.138 & 0.034 & 0.123 & 0.215 & 0.058 & 0.098 & 0.526 & 0.064 & 0.080 \\
\hline $\mathrm{p}$-value & $>0.15$ & $>0.15$ & $>0.15$ & 0.146 & $>0.15$ & $<0.01$ & $<0.01$ & $>0.15$ & $>0.15$ \\
\hline Mean $\mathrm{P}_{\mathrm{i}}$ & 1.15 & 1.00 & 1.10 & 0.88 & 1.21 & 1.21 & 1.24 & 1.51 & 1.00 \\
\hline Highest $P_{i}$ & 1.53 & 1.07 & 1.38 & 1.42 & 1.32 & 1.40 & 2.94 & 1.68 & 1.19 \\
\hline Mean $I_{\text {geo }}$ & -0.39 & -0.59 & -0.45 & -0.80 & -0.31 & -0.31 & -0.46 & 0 & -0.59 \\
\hline Highest $\mathrm{I}_{\text {geo }}$ & 0.03 & -0.49 & -0.12 & -0.08 & -0.19 & -0.10 & 0.97 & 0.16 & -0.34 \\
\hline Background & 11.2 & 12.7 & 61 & 22.6 & 29800 & 583 & 26.9 & 26 & 74.2 \\
\hline
\end{tabular}


In this study, the national soil environmental background values of China (A-layer, CEPA 1990) have been chosen to be the background, and the calculated results of $P_{i}$ values are given in Table 1. As can be seen from the table, the soils samples have mean $P_{i}$ values between 0.88 and 1.51, which indicates no $(\mathrm{Cu})$ to light (other elements) pollution. However, as can be seen from the highest $\mathrm{P}_{\mathrm{i}}$ values, four samples have $\mathrm{P}_{\mathrm{i}}$ values of $\mathrm{Ni}$ higher than 2 , which indicates moderate pollution.

Another index, the geo-accumulation index $\left(\mathrm{I}_{\mathrm{geo}}\right)$ has also been applied for the pollution assessment. The calculation of $\mathrm{I}_{\text {geo }}$ is as $\mathrm{I}_{\text {geo }}=\log _{2}\left[\mathrm{C}_{\mathrm{m}} /\left(1.5 \times \mathrm{C}_{\mathrm{s}}\right)\right]$. The classification of pollution degrees based on the $\mathrm{I}_{\text {geo }}$ values can be subdivided into five degrees: unpolluted $(<0)$, light $(0-1)$, moderate (1-3), heavy (3-5) and serious (> 5) (Praveena et al. 2008). The mean $\mathrm{I}_{\text {geo }}$ values of the samples show "unpolluted" characters for all the elements $\left(\mathrm{I}_{\text {geo }}<0\right)$, whereas some of the elements ( $\mathrm{As}, \mathrm{Ni}$ and $\mathrm{Pb}$ ) have the highest $\mathrm{I}_{\text {geo }}$ values between 0 and 1, implying that they have light pollution for some of the locations.

Different with the $P_{i}$ and the $I_{\text {geo }}$, another index, the Nemerow composite index $\left(\mathrm{P}_{\mathrm{n}}\right)$ considers all the elements rather than the single ones, the calculation of the $\mathrm{P}_{n}$ is as $\mathrm{P}_{n}$ $=\operatorname{SQRT}\left[\left(\mathrm{P}_{\mathrm{i}} \mathrm{m}^{2}+\mathrm{P}_{\mathrm{i}} \mathrm{x}^{2}\right) / 2\right]$. Where $\mathrm{P}_{\mathrm{i}} \mathrm{m}$ and $\mathrm{P}_{\mathrm{i}} \mathrm{x}$ are mean and maximum of $P_{i}$ values of the elements, respectively. Based on the $P_{n}$ values, the quality of soil can also be classified to be of five grades: safety $(<0.7)$, precaution $(0.7-1.0)$, slightly polluted (1-2), moderately polluted (2-3) and seriously polluted (>3) (Dai et al. 2008). In this study, the calculated $\mathrm{P}_{\mathrm{n}}$ values for all the samples ranged from 1.20 to 2.31 (mean $=1.44$ ), most of the samples (26) have $1.0 \leq \mathrm{P}_{\mathrm{s}}<2.0$, which means that most of the soil samples in this study can be classified to be slightly polluted.

\section{Sources of Elements}

Because some of the elements with good correlation are always considered to have similar sources, the relationships between elements can give information about their sources (Cobelo-garcía \& Prego 2004). In this study, some of the elements show close positive relationships (correlation coefficients higher than the critical value $r_{a}=0.374, a=0.05$, $\mathrm{n}=28$ ): e.g. As-Ni, Co-Fe, Co-Mn, Fe-Mn-Zn-Pb, Ni-Zn, $\mathrm{Co}-\mathrm{Cu}, \mathrm{Co}-\mathrm{Zn}$ and $\mathrm{Cu}-\mathrm{Ni}$ (Table 2). Such results suggest that their concentrations change simultaneously, and indicating that they might have been affected by similar factors, or have similar sources.

Cluster analysis has also long been used for environmental studies, especially the R-mode cluster analysis, has long been used for finding out the good relationships between elements, which might be an indication of the similar source of them (Chen et al. 1997, Chen et al. 2005). In this study, the hierarchical R-mode cluster analysis has been applied to the data, and the "Ward" linkage and the "Pearson" distance have been chosen for calculation, and the results are shown in Fig. 2 as a dendrogram. As can be seen from the figure, two main groups can be identified: As-Co-Cr-Cu-Ni (Group 1) and $\mathrm{Fe}-\mathrm{Mn}-\mathrm{Zn}-\mathrm{Pb}$ (Group 2), which indicate that the elements in the similar group have similar sources.

Factor analysis is a commonly used statistical method to classify, simplify and identify the most important variables in data sets through dimensionality reduction. During environmental studies, factor analysis has long been used for tracing elemental sources (Lin et al. 2002). In this study, based on the criteria of the initial eigenvalue ( $>1$, Kaiser criterion) (Maiz et al. 2000), two factors were obtained with total variance explanation of $64.7 \%$ (Table 3 ), the first one with strong positive loadings ( $>0.75$ ) of $\mathrm{Fe}, \mathrm{Mn}$ and $\mathrm{Zn}$ and moderate positive loadings $(0.50-0.75)$ of $\mathrm{Co}$ and $\mathrm{Pb}$, has $41.6 \%$ of the total variance explanation. The second factor is characterized by strong positive loadings of $\mathrm{Ni}$, and moderate positive loadings of $\mathrm{As}$ and $\mathrm{Cu}$ and it has $23.1 \%$ of the total variance explanation. Moreover, $\mathrm{Cr}$ has positive loading in factor 2. Such a result is similar to the results obtained by correlation and cluster analyses that two sources might be responsible for the elemental concentrations, Fe-Mn-Zn-

Table 2: Results of the correlation analysis.

\begin{tabular}{|lllllllll|}
\hline & $\mathrm{As}$ & $\mathrm{Co}$ & $\mathrm{Cr}$ & $\mathrm{Cu}$ & $\mathrm{Fe}$ & $\mathrm{Mn}$ & $\mathrm{Ni}$ & $\mathrm{Pb}$ \\
\hline $\mathrm{Co}$ & 0.191 & & & & & & & \\
$\mathrm{Cr}$ & 0.193 & -0.313 & & & & & \\
$\mathrm{Cu}$ & 0.081 & $0.430^{*}$ & 0.283 & & & & \\
$\mathrm{Fe}$ & -0.014 & $0.487^{* *}$ & -0.393 & 0.126 & & & \\
$\mathrm{Mn}$ & -0.068 & $0.536^{* *}$ & -0.445 & 0.173 & $0.941^{* *}$ & & & \\
$\mathrm{Ni}$ & $0.480^{*}$ & 0.342 & 0.026 & $0.459^{*}$ & 0.363 & 0.363 & & \\
$\mathrm{~Pb}$ & -0.177 & 0.327 & -0.408 & -0.017 & $0.495^{* *}$ & $0.615^{* *}$ & 0.035 & $0.520^{* *}$ \\
$\mathrm{Zn}$ & -0.106 & $0.402^{*}$ & -0.250 & 0.284 & $0.763^{* *}$ & $0.783^{* *}$ & $0.496^{* *}$ & \\
\hline
\end{tabular}




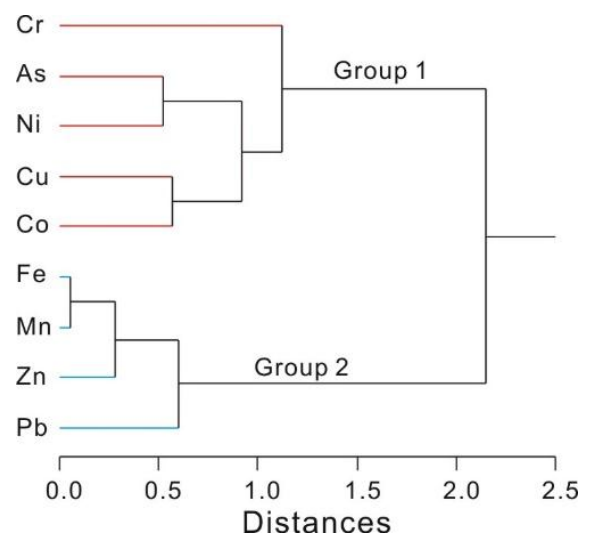

Fig. 2: Result of R-mode cluster analysis.

$\mathrm{Pb}$ and $\mathrm{As}-\mathrm{Cr}-\mathrm{Cu}-\mathrm{Ni}$ are mainly contributed by the factor (source) 1 and 2, respectively. As to the Co, both sources are responsible.

Previous studies revealed that four sources are responsible for the heavy metals (including arsenic) in the farmland soil, including the natural/geogenic processes (weathering of soil parental materials), the dust fall (mainly related to the coal combustion and traffic), agriculture (related to the application of fertilizers and pesticides, and sewage irrigation) and mining activities (Huamain et al. 1999, Wang 2019). In consideration with the natural condition of the study area, two main sources can be considered to be responsible for the soil elements in this study: the geogenic source related to the formation of the soil (weathering) and the agricultural activities (application of fertilizers and pesticides). Although Suzhou is a coal producing area, the coal combustion and coal-related industry (coal chemical industry and coal electricity) are limited, and the sampling site is far away from the coal power plant and high density of traffic way, and therefore, the contribution of coal and traffic-related pollution to the soil in this study may be limited.

Based on this consideration, factor 1 can be explained to be the geogenic source, because the most abundant element $\mathrm{Fe}$ and $\mathrm{Mn}$ has the highest positive loadings in this factor relative to the factor 2. Although some other sources can affect the Fe concentration in the soil, it is hard to exceed the background value $(29400 \mathrm{mg} / \mathrm{kg}$ ) except for the existence of iron ore. Previous studies revealed that the application of superphosphate can increase the concentration of As in the soil (Wang et al. 2010), whereas the long-term use of pesticides can increase the $\mathrm{Cu}$ and Ni concentration in the soil (Wang 2019). Moreover, $\mathrm{Cr}$ can be released by the weathering of agricultural film. Therefore, the second factor can be explained to be the
Table 3: Results of factor analysis.

\begin{tabular}{|lll|}
\hline Factor & F1 & F2 \\
\hline $\mathrm{As}$ & -0.180 & 0.644 \\
$\mathrm{Co}$ & 0.579 & 0.425 \\
$\mathrm{Cr}$ & -0.609 & 0.405 \\
$\mathrm{Cu}$ & 0.112 & 0.722 \\
$\mathrm{Fe}$ & 0.890 & 0.159 \\
$\mathrm{Mn}$ & 0.943 & 0.135 \\
$\mathrm{Ni}$ & 0.297 & 0.803 \\
$\mathrm{~Pb}$ & 0.742 & -0.206 \\
$\mathrm{Zn}$ & 0.819 & 0.265 \\
Eigen value & 3.741 & 2.082 \\
Variance explained & $41.6 \%$ & $23.1 \%$ \\
\hline
\end{tabular}

agricultural source because $\mathrm{As}, \mathrm{Cr}, \mathrm{Cu}$ and $\mathrm{Ni}$ have high positive loadings.

\section{CONCLUSIONS}

The following conclusions have been obtained:

(1) The elemental concentrations are $\mathrm{Fe}>\mathrm{Mn}>\mathrm{Zn}>\mathrm{Cr}$ $>\mathrm{Pb}>\mathrm{Ni}>\mathrm{Cu}>\mathrm{As}>\mathrm{Co}$. They have low-medium coefficients of variation (0.058-0.526) and most of them have $\mathrm{p}$-values of normal distribution test $>0.05$.

(2) The single pollution, geo-accumulation and the Nemerow composite indexes suggest that the soils in this study are no-to-slightly polluted.

(3) Statistical analyses indicate that the two sources are responsible for the soil elemental concentrations, the geogenic and agricultural.

\section{ACKNOWLEDGEMENTS}

This work was financially supported by the Natural Science Research Project of Universities in Anhui Province (KJ2020ZD64; KJ2020A0740) and the Scientific Foundation of Platform in Suzhou University (2016ykf02).

\section{REFERENCES}

CEPA (Chinese Environmental Protection Administration) 1990. Elemental Background Values of Soils in China. Environmental Science Press of China, Beijing.

Chen, T.B., Wong, J.W.C., Zhou, H.Y. and Wong, M.H. 1997. Assessment of trace metal distribution and contamination in surface soils of Hong Kong. Environmental Pollution, 96(1): 61-68.

Chen, T.B., Zheng, Y.M., Lei, M., Huang, Z.C., Wu, H.T., Chen, H., Fan, K.K., Yu, K., Wu, X. and Tian, Q.Z. 2005. Assessment of heavy metal pollution in surface soils of urban parks in Beijing, China. Chemosphere, 60(4): 542-551.

Cobelo-García, A. and Prego, R. 2004. Influence of point sources on trace metal contamination and distribution in a semi-enclosed industrial 
embayment: the Ferrol Ria (NW Spain). Estuarine, Coastal and Shelf Science, 60(4): 695-703.

Dai, J., Li, S., Zhang, Y., Wang, R. and Yu, Y. 2008. Distributions, sources and risk assessment of polycyclic aromatic hydrocarbons (PAHs) in topsoil at Ji'nan city, China. Environmental Monitoring and Assessment, 147(1-3): 317-326.

Duan, Y.L. 2017. Development current situation and measures of plateau characteristic planting industry in Gannan Zhou. Journal of Animal Science and Veterinary Medicine, 36(1): 56-57+61.

Fu, J.M., Shi, Z.G., Sun, L.H., Zhang, Y., Su, H.M. and Fang, G. 2009. Investigation and analysis on soil organic matter in Dangshan County of Anhui Province. Journal of Anhui Agriculture Science, 37(28): 13745-13746.

Huamain, C., Chunrong, Z., Cong, T. U. and Yongguan, Z. 1999. Heavy metal pollution in soils in China: status and countermeasures. Ambio, 28(2): 130-134.

Huang, Y., Li, T., Wu, C., He, Z., Japenga, J., Deng, M. and Yang, X. 2015. An integrated approach to assess heavy metal source apportionment in peri-urban agricultural soils. Journal of Hazardous Materials, 299: 540-549.

Liang, J., Chen, C., Song, X., Han, Y. and Liang, Z. 2011. Assessment of heavy metal pollution in soil and plants from Dunhua sewage irrigation area. International Journal of Electrochemical Science, 6(11): 5314-5324.

Lin, E.X. 2020. The effective way to break through the rural revitalization strategy. Journal of Harbin University, 41(1): 43-46.

Lin, Y.P., Teng, T.P. and Chang, T.K. 2002. Multivariate analysis of soil heavy metal pollution and landscape pattern in Changhua county in Taiwan. Landscape and Urban Planning, 62(1): 19-35.

Liu, F.Y. and Gu, C.Y. 2011. Current status, problems and development tactics of unique planting industry for Beijing Mentougou District. Beijing Agriculture, 6: 13-14+16.

Maiz, I., Arambarri, I., Garcia, R. and Millan, E. 2000. Evaluation of heavy metal availability in polluted soils by two sequential extraction procedures using factor analysis. Environmental pollution, 110(1): 3-9.

Ning, X. 2019. Pan-agriculture: agricultural transformation in the Rural
Vitalization. Journal of China Agricultural University (Social Sciences), 36(6): 5-12.

Praveena, S.M., Ahmed, A., Radojevic, M., Abdullah, M.H. and Aris, A.Z. 2008. Heavy metals in mangrove surface sediment of Mengkabong lagoon, Sabah: multivariate and geo-accumulation index approaches. International Journal of Environmental Research, 2(2): 139-148.

Qiao, J.J. and Wang, H.F. 2012. Spatial-temporal variation of villagelevel economy development based on characteristic planting in less developed regions-A case study of Shilipu Village in Henan Province. Human Geography, 2: 82-86

Radu, T. and Diamond, D. 2009. Comparison of soil pollution concentrations determined using AAS and portable XRF techniques. Journal of Hazardous Materials, 171(1-3): 1168-1171.

Sarkar, D., Datta, R. and Hannigan, R. 2011. Concepts and Applications in Environmental Geochemistry (Vol. 5). Elsevier.

Sun, L.H. 2020. Pollution assessment and source approximation of trace elements in the farmland soil near the trafficway. Journal of Environmental Engineering and Landscape Management, 28(1): 20-27.

Sun, L.H. and Feng, S.B. 2019. Heavy metals in the surface soil around a coalmine: Pollution assessment and source identification. Polish Journal of Environmental Studies, 28(4): 2717-2724.

Sun, L.H. and Gui, H.R. 2014. Source identification of heavy metals in river sediments by using factor analysis in combination with k-means cluster analysis. Nature Environment and Pollution Technology, 13(1): 73-77.

Wang, G.L., Li, L.K., Hao, M.D. and Zhang, M. 2010. Effects of long-term fertilization on heavy-metal contents of soil and environmental quality evaluation. Journal of Soil and Water Conservation, 24(3): 60-63.

Wang, N. 2019. Study and analysis of sources of heavy metal pollution in farmland soil. China Metal Bulletin, 1: 289-290.

Wu, Y.D., Xiang, F. and Zhao, J.H. 2010. Approach to relationship between Huangshan tea quality and geological background of growing areas. Resources Survey \& Environment, 31(1): 39-49.

Zhao, Z.H. 2013. Reduction and control for agriculture pollution in Suzhou City of Anhui Province. Environmental Protection and Technology, 19(5): 47-48 